\title{
Decolorization of Low Molecular Compounds of Seaweed by Using Activated Carbon
}

\author{
S. M. Anisuzzaman, Awang Bono, Duduku Krishnaiah, and Norazwinah Azreen Hussin
}

\begin{abstract}
Commercially available carrageenan powder which is extracted from seaweed possesses yellowish color and off-odor that deter their usage in human food, pharmaceutical and cosmetic industries. The objective of this study was to investigate of decolorization of low molecular compounds of seaweed using activated carbon (AC). The effects of changes on AC dosage, temperature and contact time were investigated. The effect of color concentration was analysed using Hunter Laboratories ColorFlex ${ }^{\circledR}$ Colorimeter. Colors were measured in reflectance mode using the Hunter $\mathrm{L}$ a b system, with D65 as the illuminant and a $10^{\circ}$ standard observer angle. It was observed that an increase in activated carbon dosage decreases color. UV VIS Spectrophotometer was used to investigate whether adsorbed sample gives an effect to the molecular compounds before and after $\mathrm{AC}$ addition. In conclusion, the treatment using AC gives complete decolorization of carrageenan solution. This study also confirms contact time not really affected on bleaching process.
\end{abstract}

Index Terms-Seaweed, carrageenan, semi refined carrageenan, adsorption, activated carbon.

\section{INTRODUCTION}

Seaweed is very common for people since the plant is rich in vitamins (vitamins B1, B2, B6, B16, C, and niacin) and minerals mainly calcium, sodium, magnesium, potassium, iodine, iron, and zinc [1], [2].

Carrageenan is well known also because of the low cost in production and nontoxic metal, sources of antioxidants, antimicrobials, and other bioactive agents. Carrageenan are the excellent source of bioactive compounds such as carotenoids, dietary fibre, protein, essential fatty acids, vitamins and minerals [3], [4] Besides, this can regulate with hormones to speed up the metabolism and promote a young looking skin color and well-being.

Nowadays, carrageenan extract is used in animal food and in industrial uses as stabilizer, gelling and thickening agent. Current commercially carrageenan powder possesses yellowish color and off-odor that deters their usage in human food, pharmaceutical and cosmetic industries as additive to improve food texture, gelation stability and viscosity.

Seaweed's cell walls contain polysaccharides, which

Manuscript received August 5, 2013; revised November 25, 2013. This work was supported in part by the Universiti Malaysia Sabah under Grant SLB0017-TK-2012.

S. M. Anisuzzaman, Awang Bono, and Duduku Krishnaiah are with the School of Engineering and Information Technology, Universiti Malaysia Sabah, Malaysia (tel.: 088-320000; e-mail: anis_zaman@umsedu.my, bono@ums.edu.my, krishna@ums.edu.my).

Norazwinah Azreen Hussin was with the Universiti Malaysia Sabah. She is now with the School of Engineering and Information Technology, Malaysia (e-mail: azwienah@yahoo.com). include agar, alginates, carrageenans [1], and also minor compounds such as fucoidan and laminarin [5]. All the compounds have their own ability and roles such as, capacity to form gel, metal chelating, and other actions.

Agar can be defined as a hydrophilic colloid extracted from certain seaweed from the Rhodophyceae class and it is insoluble in cold water but soluble in boiling water. It is a mixture of polysaccharides which is the basic monomer of galactose and it can be sulphated in very variables degrees but to lesser degree than carrageenan [6].

Extraction process act to removes coloring matter and some proteins and makes the gum more easily extractable. 6-sulfate may also eliminate in some extraction process. Basket of seaweed immersed and cooked in alkali solution and then soaked with fresh water to naturalized most of the residual alkali [7]. Kappaphycus alvarezii (Euchema cottoni) is used in this process because it contains mainly kappa $(k)$ carrageenan and this is the carrageenan that forms a gel with potassium salts. Iota-containing seaweeds can also be processed, although the markets for iota $(i)$ carrageenan are significantly less than those for kappa. Lambda $(\lambda)$ carrageenans do not form gels with potassium and would therefore dissolve and be lost during the alkali treatment [8].

Activated carbon was first known to treat water over 2000 years ago. However, it was first produced commercially at the beginning of the 20th century and was only available in powder form. Initially activated carbon was mainly used to decolorize sugar and then from 1930 for water treatment to remove taste and odor [9].

The adsorption power of the AC is in the range of $90 \%$ $110 \%$ of the declaration value [10]. Besides, activated carbon is economically saved because of its low price but its cost is not too low enough to a large consumption of adsorption sites other than the intended compound to be removed [11]. As mention by Jensen, B., 2009, the AC is widely used because of it is a low cost adsorbent [12].

Decolorizing applications involve removal of large molecular compounds which require AC with a well-developed macropore structure [13]. AC is employ as a color removing agent (adsorbent) due to its economic advantage over other adsorbents. It finds wide application in food, pharmaceuticals, solvent recovery, drinking water treatment, fuel cells, chemical and other process industries [14]. AC is non-specific adsorbents that not only bind the color components, but also the protein components and odor components [15].

The aim of this study was to investigate decolorization and deodorization of low molecular compound of seaweed by using AC. Therefore, color concentration analysis was 
conducted to observed influence of AC dosage and contact time.

\section{MAterials AND MethodS}

\section{A. Preparation of Raw Seaweed}

Raw seaweed, Kappaphycus alvarezii, was collected from UMS Seaweed Research Farm, Semporna which prepared by sun drying. Sundried seaweed was washed thoroughly with distilled water for two reasons; to remove contaminants and to standardize the moisture content of the seaweed. Wet seaweed was then dried in oven at $60^{\circ} \mathrm{C}$ for $15-16$ hours to remove the excess moisture [7], [16].

\section{B. Extraction of Seaweed}

The dried seaweed was extracted in batch cooker in potassium hydroxide $(\mathrm{KOH})$ solution. The extraction temperature, $\mathrm{KOH}$ concentration and extraction time were controlled at $75^{\circ} \mathrm{C}, 74.70 \mathrm{~min}$ and $6.70 \% \mathrm{KOH}$ concentration. The extracted seaweed was then cooled to room temperature and washed with distilled water to remove the excess $\mathrm{KOH}$ [17]. This processed seaweed was classified as semi refined carrageenan (SRC).

\section{Adsorption Procedure}

The AC granules were sieved to remove fine carbon powder and were dried overnight in oven at $100^{\circ} \mathrm{C}$. Various ratios of activated carbon were weighed into flask with 200 $\mathrm{mL}$ of sample. All the flasks were then sealed shut with aluminum foil. Each flask were shaken and immersed at water bath with $50 \mathrm{rpm}$ for desired value of temperature and contact time. After shaking with manipulated temperature, the contact time was stopped, then the AC settled and the liquid of sample was decanted into graduated cylinder to measure volume recovered. Measuring the decanted volume ensures an accurate concentration of the seaweed gel solution calculation [18].

\section{Removal of Activated Carbon from Decolorized Solution}

The granulated AC from decolorized solution settled at bottom of flask was screened at laboratory lab (ASTM standard, No: 20, nominal sieve opening: $0.850 \mathrm{~mm}$ ) and used to sieve AC after adsorption process [17].

\section{E. Color Concentration Analysis}

For color analysis, $25 \mathrm{ml}$ of adsorption sample was put on the glass sample cell and the reading showed on the screen display and was recorded as a result. A Hunter Laboratories ColorFlex ${ }^{\circledR}$ Colorimeter was used to quantify the color of the carrageenan solution. This colorimeter gives reading of 3-dimensional rectangular space with D65 as the illuminant and $10^{\circ}$ standard observer angles [18].

\section{F. UV-VIS Spectrophotometry Analysis}

A total of $0.1 \mathrm{ml}$ sample was diluted to $1.5 \mathrm{ml}$ with $\mathrm{H}_{2} \mathrm{O}$, and then this mixture was spiked with $1 \mathrm{ml}$ phenol (5\%) and 4 $\mathrm{ml} \mathrm{H}_{2} \mathrm{SO}_{4}$. Color reaction was performed at $30^{\circ} \mathrm{C}$ for $35 \mathrm{~min}$. Spectrophotometry conditions in the assay was 200-600 nm as its full-scan wavelength, with the slow scanning speed 2 $\mathrm{nm}$ as the broadband spectrum and $488 \mathrm{~nm}$ as the detection wavelength [19].

\section{RESUlTS AND DISCUSSION}

\section{A. Data Analysis}

The data was entered and analysed into Microsoft Excel (Microsoft Corporation, Redmond, USA) CIE-Lab values were used to calculate a value for color change $(\Delta E)$ by using the following equations [20]:

$$
\Delta E=\left[\left(\Delta L^{*}\right)^{2}+\left(\Delta a^{*}\right)^{2}+\left(\Delta b^{*}\right)^{2}\right]^{1 / 2}
$$

The $\Delta E$ between initial or reference with the final colors was then calculated.

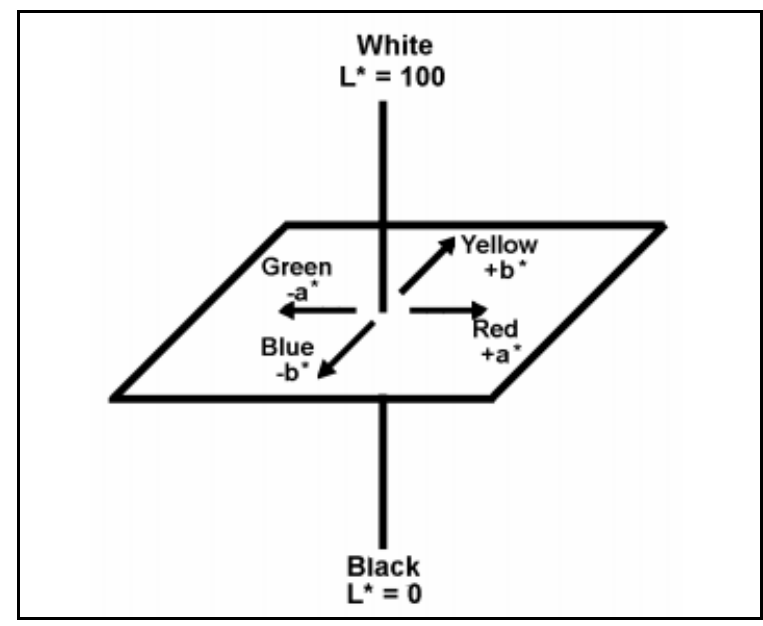

Fig. 1. CIELAB color space.

Fig. 1 shows CIELAB color space. The parameter $L$ represents lightness or darkness with $L=100$ representing white and $L=0$ representing black, positive a represents red, negative a represents green, positive $b$ represents yellow, and negative $b$ represents blue.

TABLE I: COLORIMETER DATA

\begin{tabular}{|c|c|c|c|c|c|}
\hline Exp & $\begin{array}{c}\text { Dosage } \\
(\mathrm{g} / \mathrm{mL})\end{array}$ & $\begin{array}{c}\text { Time } \\
(\mathrm{hr})\end{array}$ & $L^{*}$ & $a^{*}$ & $b^{*}$ \\
\hline 1 & 0.00 & - & 58.90 & 0.61 & -2.57 \\
\hline 2 & 0.05 & 24 & 60.72 & 0.51 & 4.53 \\
\hline 3 & 0.10 & 24 & 75.98 & 0.47 & 4.85 \\
\hline 4 & 0.20 & 24 & 81.19 & 0.38 & 5.19 \\
\hline 5 & 0.30 & 24 & 86.32 & 0.22 & 5.85 \\
\hline 6 & 0.05 & 48 & 61.13 & 0.50 & 4.57 \\
\hline 7 & 0.10 & 48 & 76.09 & 0.44 & 4.89 \\
\hline 8 & 0.20 & 48 & 81.86 & 0.36 & 5.20 \\
\hline 9 & 0.30 & 48 & 86.75 & 0.24 & 5.92 \\
\hline
\end{tabular}

The data on color measurement is shown in Table I with manipulated dosage of $\mathrm{AC}(\mathrm{g} / \mathrm{ml})$ and time contact $24 \mathrm{hr}$ and $48 \mathrm{hr}$.

\section{B. Influence of AC Dosage}

Experimental results indicated in Fig. 2 shows an increase in AC dosage increases color reduction. $L^{*}$ value were increase as increases dosage of adsorbent. It shows that color changes from darkness to lightness with maximum 
decolorized $L^{*}$ at 86.75 . Fig. 3 shows that color change $(\Delta E)$ increases as dosage of $\mathrm{AC}$ added. Thus, decolorization prior to total placement of $\mathrm{AC}$ produced significantly greater $\Delta E$ than pacing none of $\mathrm{AC}$.

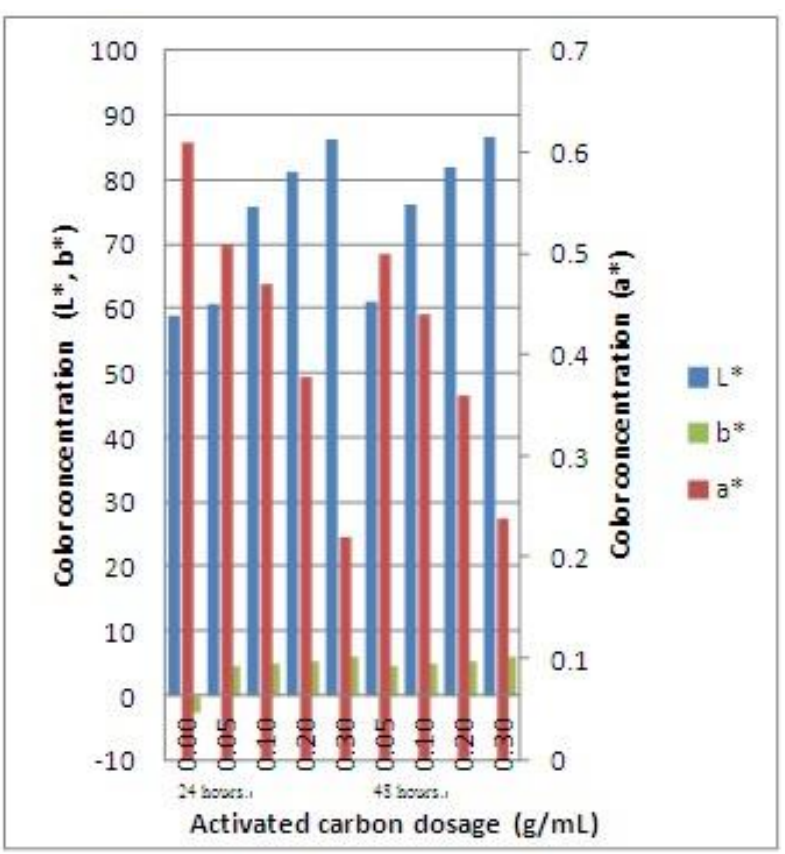

Fig. 2. Effect of different adsorbents dosage and contact time on decolorization of carrageenan gel solution.

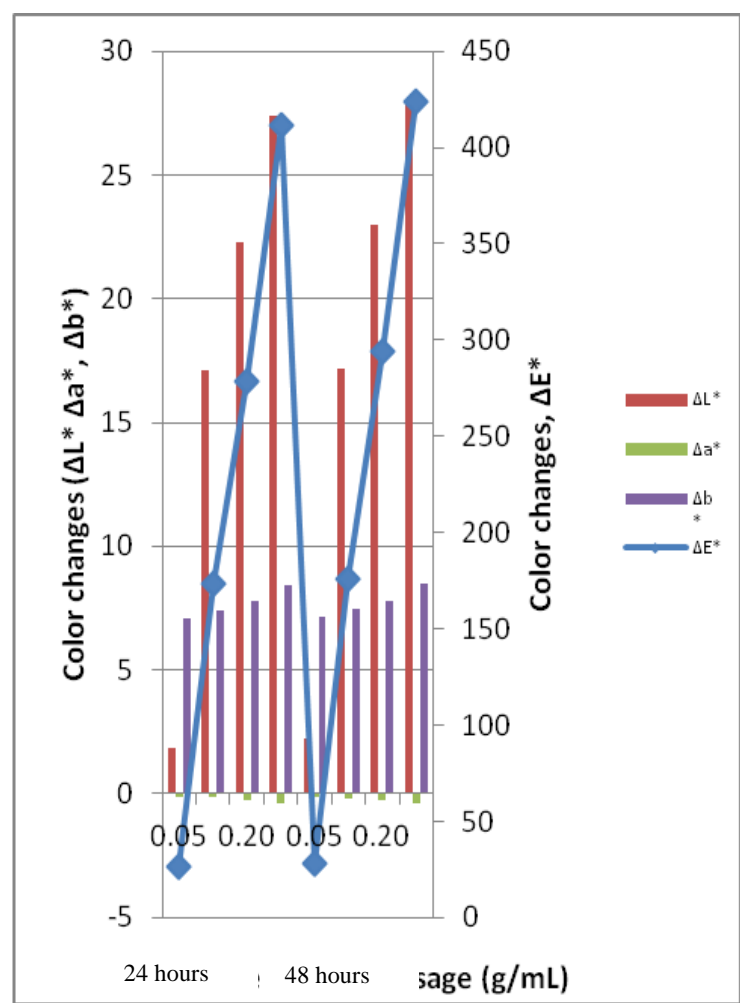

Fig. 3. Mean color changes from non-bleached to bleached carrageenan gel solution.

\section{Influence of Contact Time}

Based on Fig. 2 shows that influence of contact time with decolorization of low molecular compounds. In some cases, with increasing time, color rises around 0.20 to 0.40 units. However, the changes are very small. Furthermore, it was mentioned that the duration of bleaching is responsible for the problem of color reversion [21]. Hence 24 hours seems better than 48 hours.

\section{Molecular Compound Analysis}

The carrageenan solution before and after the activated carbon solution was analysed using UV-VIS Spectrophotometry. This analysis only to investigate effect of adsorption color for the sample, not on measure or to identify molecular compound in carrageenan.

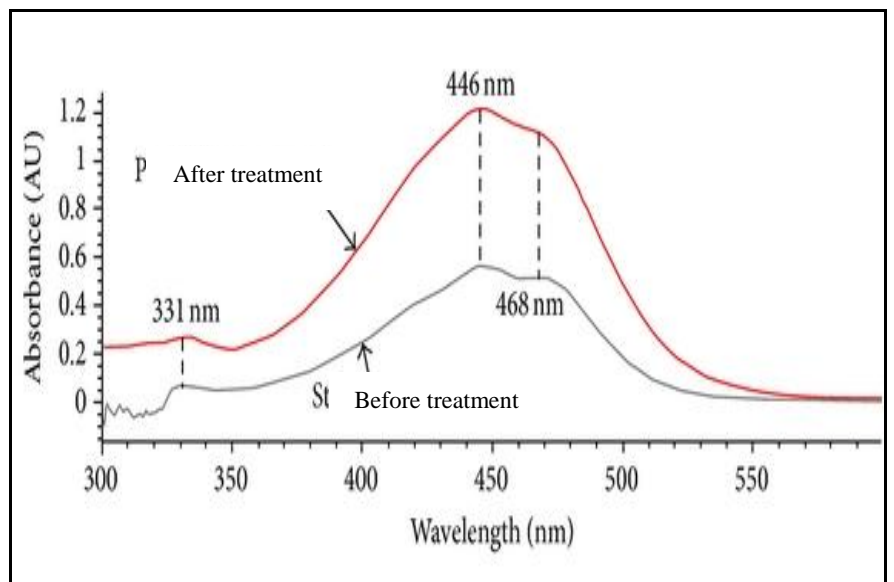

Fig. 4. Molecular compound of seaweed before and after treatment with activated carbon.

In this regard, the UV-visible spectrum of the treated compound (added with activated carbon) was recorded and its absorption maximum $\left(\lambda_{\max }\right)$ was compared with the untreated sample. Results can be seen from Fig. 4 that both the treated and untreated sample exhibited the same spectroscopic profile with similar $\lambda_{\max }(331,446$, and $468 \mathrm{~nm})$. This clearly shows that there is adsorption process occurs. It is believe that the absorbent have an impact on the adsorption of color in sample. The color of sample becomes brighter by addition of $\mathrm{AC}$.

\section{CONCLUSION}

Within in the limitation of this study, it can be concluded that the highest color change was produced by AC dosage at $0.3 \mathrm{~g} / \mathrm{mL}$. The least change was produced by contact time at 24 hours and dosage of $\mathrm{AC}$ at $0.05 \mathrm{~g} / \mathrm{mL}$. There were no significant difference in the color change $(\Delta \mathrm{E})$ produced with respect to contact time. Absorbance value for treated sample (at 24 hours and $0.05 \mathrm{~g} / \mathrm{mL}$ ) increased when compared with untreated sample. Hence, AC is a good decolourizing agent used to adsorb the color and odor of seaweed sample.

\section{ACKNOWLEDGEMENT}

The authors wish to acknowledge the financial support from Universiti Malaysia Sabah under the UMS grant number SLB0017-TK-2012.

\section{REFERENCES}

[1] I. L. Lopez, S. Bastida, C. R. Cappilas, L. Bravo, M. T. Larrea, F. S. Muniz, S. Cofrades, and F. J. Colmenero, "Composition and antioxidant capacity of low salt meat emulsion model systems 
containing edible seaweeds," Journal of Meat Science, vol. 83, pp 492-498, 2009

[2] M. Caliceti, E. Argese, A. Sfriso, and B. Pavoni, "Heavy metal contamination in the seaweed of the vanice lagoon," Journal of Chemosphere, vol. 48, pp. 443-545, 2001.

[3] J. Fleurence, "Seaweed proteins: Biochemical, nutritional aspects and potential uses," Trends Food Sci. Technol, vol. 10, pp. 25-28, 1999.

[4] N. Bhaskar and K. Miyashita, "Lipid Composition of Padina Tetratomatica (Dictyotales, Pheophyta), A brown seaweed of the west coast of India," J. Fish, Indian, vol. 52, pp. 263-268, 2005.

[5] L. E. Rioux, S. L. Turgeon, and M. Bealieu, "Effect of season on the composition of bioactive polysaccharides from the brown seaweed saccharina longicruris," Journal Phytochemistry, vol. 70, pp 1069-1075, 2009.

[6] R. Armisen and F. Galatas, "Chapter 1 - Production, properties and uses of agar, from production and utilization of products from commercial seaweeds," Fisheries and Aquaculture Technical Paper, FAO, no. 288. pp. 1-57. 1987.

[7] A. Bono, S. M. Anisuzzaman, and O. W. Ding, "Effect of process conditions on the gel viscosity and gel strength of Semi-Refined Carrageenan (SRC) produced from seaweed (Kappaphycus Alvarezii)," Journal of King Saud University: Engineering Sciences, 2012.

[8] D. J. McHugh, "A guide to the seaweed industry," Fao Fisheries Technical Paper, FOA, Rome, no. 441, pp. 61-105, 2003.

[9] A. C. Lua and J. Guo, "Characterization of chars pyrolyzed from oil palm stone for the preparation of activated carbons," Journal of Analytical and Applied Pyrolysis, vol. 46, pp. 113-125, 1998.

[10] $37^{\text {th }}$ JECFA, 1990, Activated Carbon, FNP 52(1992) superseding specifications prepared at the 31st JECFA (1987), FNP 38(1988), Metals and arsenic specifications reviewed at the 61st JECFA (2003), No ADI was established at the 31st JECFA (1987).

[11] Y. B. Lin, B. Fugetsu, N, Terui, and S. Tanaka, "Removal of organic compounds by alginate gel beads with entrapped activated carbon," Journal of Hazardous Materials, vol. 120, pp. 237-241, 2005.

[12] B. Jensen, "Modeling Trapping Mechanism for PCB Adsorption on Activated Carbon," Thesis in Process Technology for Master of Science, Department of Physics and Technology, University of Bergen, Norway, 2009

[13] O. S. Azeez, "Decolourization of gum Arabic using activated charcoal," Journal of Science, vol. 7, pp. 23-32, 2005.

[14] B. G. P. Kumar, K. Shivakamy, L. R. Miranda, and M. Velan, "Preparation of steam activated carbon from rubberwood sawdust (hevea brasiliensis) and its adsorption kinetics," Journal of Hazardous Materials, pp. 922-979, 2006

[15] D. J. Sessa and D. E. Palmquist, "Decolorization of zein via activated carbons and molecular sieves," Industrial Crops and Products, vol. 30 pp. 162-164, 2009

[16] S. M. Anissuzaman, A. Bono, A. H. Norazwinah, and H. Y. Wong, "Effect of extraction process conditions on semi refined carrageenan produced by using spray dryer," Journal of Applied Sciences, 2013.

[17] H. D. Ozsoy and J. H. V. Leewen, "Removal of color from fruit candy waste by activated carbon adsorption," Journal of Food Engineering, vol. 101, pp. 106-112, 2010.

[18] M. J. Morton, D. L. William, H. B. Hjorth, and J. H. Smith, "Machine-smoking studies of cigarette filter color to estimate tar yield by visual assessment and through the use of a colorimeter," Regulatory Toxicology and Pharmacology, vol. 56, pp. 321-331, 2009
[19] R. Gaurav and N. A. Ghannam, "Isolation and partial characterization of bioactive fucoxanthin from himanthalia elongata brown seaweed: A TLC-based approach," International Journal of Analytical Chemistry, 2013.

[20] CIE publication No 15.2. CIE Colourimetry, 2nd Edition, Paris: Central Bureau of the CIE 1986.

[21] Coorperative work on German Society for Fat Science by the Study Group, "Technologies for industrial processing of fats and oils," Journal Lipid Science Technology, Special issue: Bleaching of fats and oils, Eur, vol. 103, pp. 499-558, 2001.

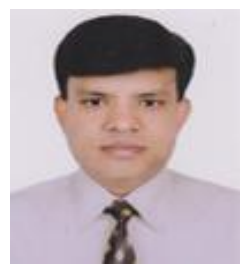

S. M. Anisuzzaman is with School of Engineering and Information Technology, Universiti Malaysia Sabah, Malaysia since 2010. (Corresponding author's phone: 088-320000 ext: 3222; fax: 088-320348; email: anis_zaman@ums.edu.my). S. M. Anisuzzaman obtained Ph.D. degree in Chemical Engineering in 2011 from Russian Sate University of Oil and Gas, Moscow, Russia in 2001. His research mainly focuses on the heterogeneous catalysis $\&$ adsorption separation and process safety.

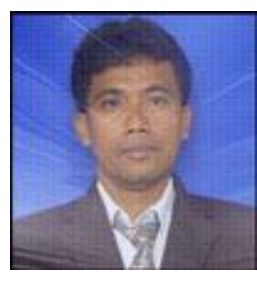

Awang Bono is with the School of Engineering and Information Technology, Universiti Malaysia Sabah, Malaysia since 1999, email bono@ums.edu.my. Awang bono obtained Ph.D. degree in Chemical Engineering from University of Surrey, Guildford, Surrey GU2 5XH, England. His research mainly focuses on separation processes, material technology and products formulation.

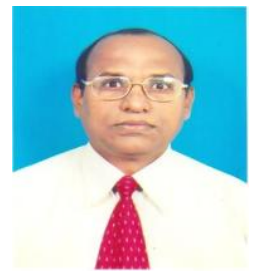

Duduku Krishnaiah is with the School of Engineering and Information Technology, Universiti Malaysia Sabah, Malaysia since 2001 , email: krishna@ums.edu.my. Duduku Krishnaiah obtained Ph.D. degree in Chemical Engineering from Indian Institute of Technology, Bombay, India in 1985.He has been on visiting assignments to Osaka University, Japan. His research mainly focuses on encapsulation processes, and carbon capture.

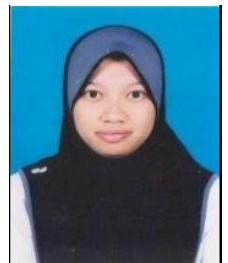

Norazwinah Azreen Hussin was with Universit Malaysia Sabah. She is now with the School of Engineering and Information Technology, Malaysia. Her email is azwienah@yahoo.com. She got her bachelor of Chemical Engineering, UMS, Malaysia, 2011. 